\title{
Rock mass assessment — what goes wrong?
}

\author{
A Duran Pells Sullivan Meynink, Australia
}

\begin{abstract}
The use of the Geological Strength Index (GSI) to assess rock mass quality in combination with the Hoek-Brown rock mass shear strength criteria has become widely used within the geotechnical fraternity to assess stability for mine pit slopes.

Two approaches for the assessment of GSI appear within the literature. Firstly, quantitative approaches as proposed by Cai et al. (2004), Hoek et al. (2013), Russo (2009) and Sonmez and Ulusay (2002). Secondly, a visual approach Marinos and Hoek (2000), Bertuzzi et al. (2016), Pells et al. (2016) and Russo (2009) and with the latter three set of authors indicating comparable assessment by either the visual or quantitative approach. Moreover, recent discussions also present qualifications and applicability of GSI by Carter and Marinos (2014) and Kaiser et al. (2015).

Based on the author's experience the findings of the above studies are discussed. Examples are utilised to highlight aspects of rock mass quality assessment where geotechnical logging of borehole core is often the only source of evaluation. The author presents two case studies where it has been possible to compare the results of the available quantification schemes with back-analysed strengths from large scale pit instability.
\end{abstract}

\section{Introduction}

The use of GSI to assess rock mass quality, initially defined by Hoek et al. (1995) and with ongoing development over time (Carter \& Marinos 2014, Marinos \& Hoek 2000, 2001, and Marinos 2010) in combination with the Hoek-Brown rock mass shear strength (HB) criterion, Hoek and Brown (1980), have become widely used within the geotechnical fraternity to assess stability for mine pit slopes.

The implementation of the $\mathrm{HB}$ criterion is clear through the equations and examples provided in the literature of Hoek and Brown (1980, 1997).

The evaluation of GSI, its development over time and its applicability to different lithological terrains are discussed in detail within Hoek et al. (1998), Marinos and Hoek (2000, 2001), Marinos et al. (2005), Marinos (2010) and Carter and Marinos (2014). Recent discussions provide; a manner in which to quantify GSI, Hoek et al. (2013), a detailed history in development, Carter and Marinos (2014), and clarification and limitations in the use of GSI, Kaiser et al. (2015).

Additional researchers have provided alternative approaches to the quantification of GSI and these chronologically include Sonmez and Ulusay (1999, 2002), Cai et al. (2004) and Russo (2009).

Much of the discussions from the above authors are largely centred on the applicability of GSI to tunnels and for slopes of limited heights (typically less than $40 \mathrm{~m}$ ). In the author's experience with stability of large pit slopes in mines, which may typically exceed hundreds of metres in height and which often rely heavily on borehole data, assessment and application of GSI requires careful consideration. This paper describes some of the key aspects of contention in the use of GSI and these comprise:

- Block formation, scale and implied limitations to applicability of GSI.

- Interlocking.

- Quantification of GSI.

Two case examples are provided of mine pit slopes where back-analysis allows comparison with the $\mathrm{HB}$ criterion resulting from the available quantification methods. 


\section{Block formation, scale and applicability}

Hoek (1983), in providing development of the HB criterion, cited the work of Ladanyi and Archambault (1970) and with particular reference to results of loading of a brick wall model, Figure 1(a). The author notes that the brick wall model has only two sets of continuous defects, one shown in the sketch of the plane and the other being the free face of the loading plane. The cross-joints in the model are noted as being discontinuous. Interestingly, Hoek and Brown (1980) noted that the HB criterion provided strength estimates which were typically higher than the actual results of testing of the brick wall model.

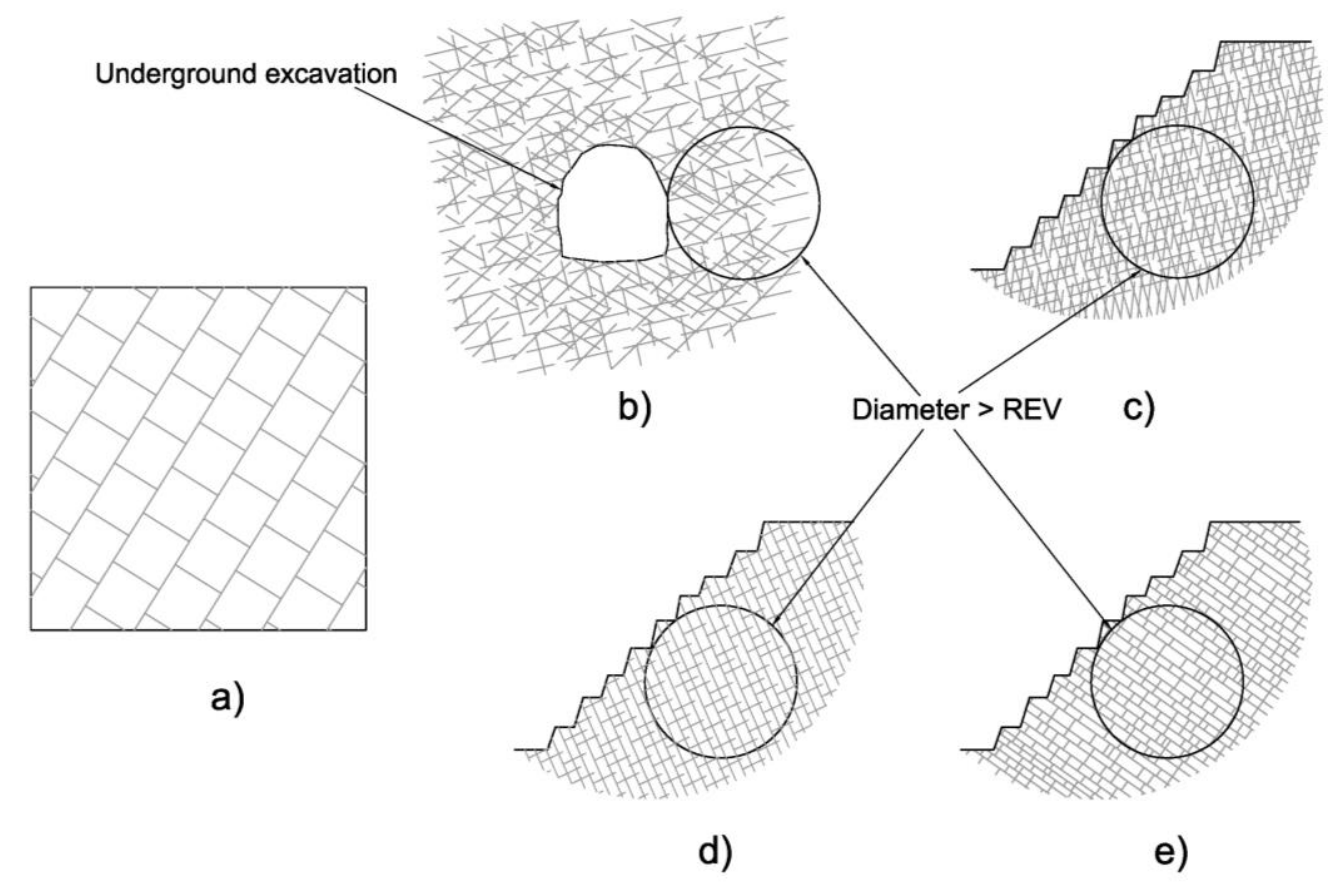

Figure 1 (a) Brick wall model of Ladanyi and Archambault (1970) as cited in Hoek (1983), conceptual scale at which HB criterion is applicable in a rock mass: (b) Hoek and Brown (1980),

(c) Hoek (1983), (d) Hoek et al. (2013) and (e) Carter and Marinos (2014)

Hoek and Brown (1980) and Hoek (1983) provided clarification on the applicability of the HB criterion with particular regard to block formation and relevance to scale, Figures $1(b)$ and $1(c)$. It is interesting to note that in both early depictions three defect sets/orientations are evident in the plane: only one set has continuities which approach the scale of the problem, the other two sets have decreasing scales of continuity and the least continuous defects often terminate within blocks. The author notes that in Figure $1(b)$ the scale for applicability of rock mass strengths is of the order of 6 to 10 blocks and increasing to 12 to 20 blocks in Figure 1(c). The latter is in keeping with the results of modelling presented by Cundall et al. (2008), whereby once the scale exceeds 10 to 15 block dimensions, the rock mass strength asymptotes and reaches the representative elementary volume (REV), a concept presented by Cunha (1990) as cited in Cundall et al. (2008). This is somewhat intuitive as most practitioners accept that when dealing with slopes, the scale of the problem well exceeds the block size, and hence once the slope scale exceeds the REV, the circles shown in Figures $1(\mathrm{~b})$ to $1(\mathrm{e})$, the HB criterion is applicable. The author highlights that the underground excavation span noted in Figure 1(b) has similar dimensions to the REV.

Similar sketches indicating block formation and scale are presented in Hoek et al. (2013), Figure 1(d) and Carter and Marinos (2014), Figure 1(e). However, both sketches show differences to Figures 1(b) and 1(c) and most notably: both only show two defect sets, one defect set has a continuity which is significantly less than the REV and akin to the cross-joints shown in 1(a) and the other set has continuity over the full slope height. For the scale of many mine pit slopes, the latter defects would imply regional scale faults. However, in the author's experience it is typically uncommon to encounter such frequency of faulting in a mine pit slope. 
Confusingly, recent discussion by Kaiser et al. (2015) highlights that the GSI and HB criteria are not applicable unless three or more defect sets are continuous at the REV scale, Figure 2. This aspect of full continuity of at least three sets at the REV scale is not evident in Figures 1(b) to 1(e). If one accepts the requirement for continuity of defect sets as presented by Kaiser et al. (2015), it implies that unless one is dealing with a heavily deformed rock mass, the HB criterion is simply not applicable for most large scale pit slopes. Kaiser et al. (2015) indicates that where defect continuities are not continuous at the REV scale, the HB criterion will underestimate rock mass strengths. This appears contradictory to the findings of Hoek and Brown (1980) in relation to the brick wall model discussed previously, where the cross-joints displayed limited continuity and wherein the HB criterion was found to over-predict strengths.

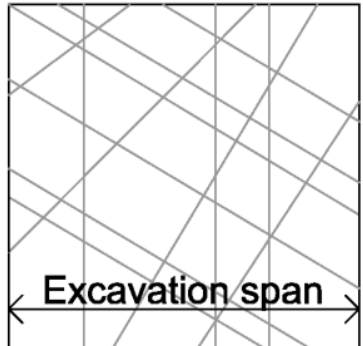

a)

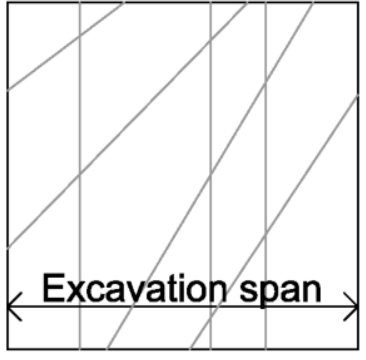

b)

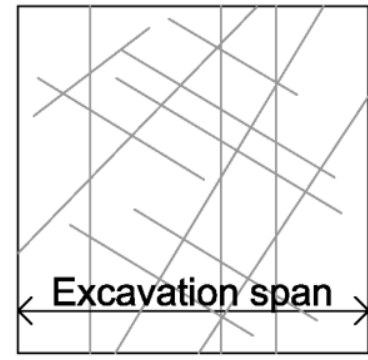

c)

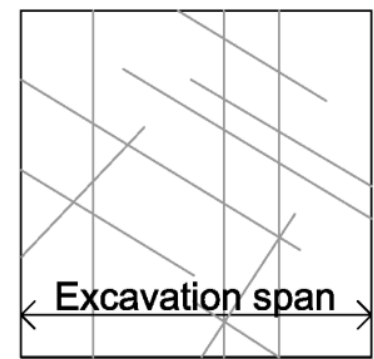

d)

Figure 2 Conceptual models presented by Kaiser et al. (2015); GSI and HB criterion applicable for (a) and deemed inapplicable for (b), (c) and (d)

Whilst the concepts provided by Kaiser et al. (2015) in Figure 2 apply to geological terrains where polyhedral blocks are likely to be present, the author highlights that in many undeformed sedimentary deposits, although bedding partings are often continuous, cross-cutting joints are often discontinuous and confined within bedding partings (as noted in Figures $1(\mathrm{a})$ and $1(\mathrm{e})$ ). Furthermore these joints may be commonly absent from adjacent beds, Figure 3. As such, if one accepts the findings of Kaiser et al. (2015) this implies that for pit slopes in many undeformed sedimentary deposits (defined by Hoek et al. (2005) as fissile Molasse) GSI is not applicable.

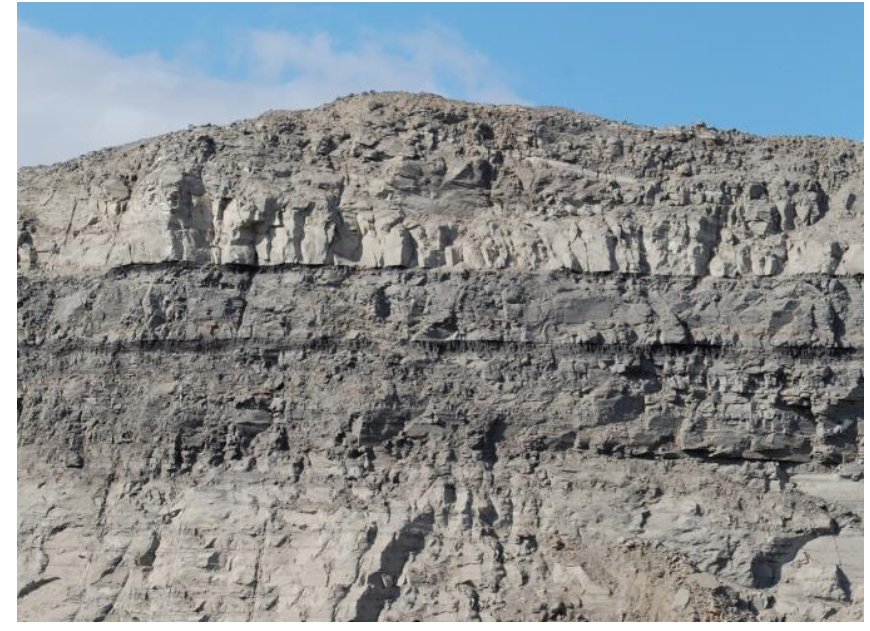

Figure 3 Undeformed sedimentary rock mass, field of view $(\sim 30 \mathrm{~m})$ 


\section{$3 \quad$ Interlocking}

Hoek and Brown (1980) highlighted that "the degree of interlocking of blocks of intact rock is of major significance in behaviour since this will control the freedom of blocks to rotate". This is evident in Figures 4 and 5 wherein 'interlocked' is a key descriptor in GSI.

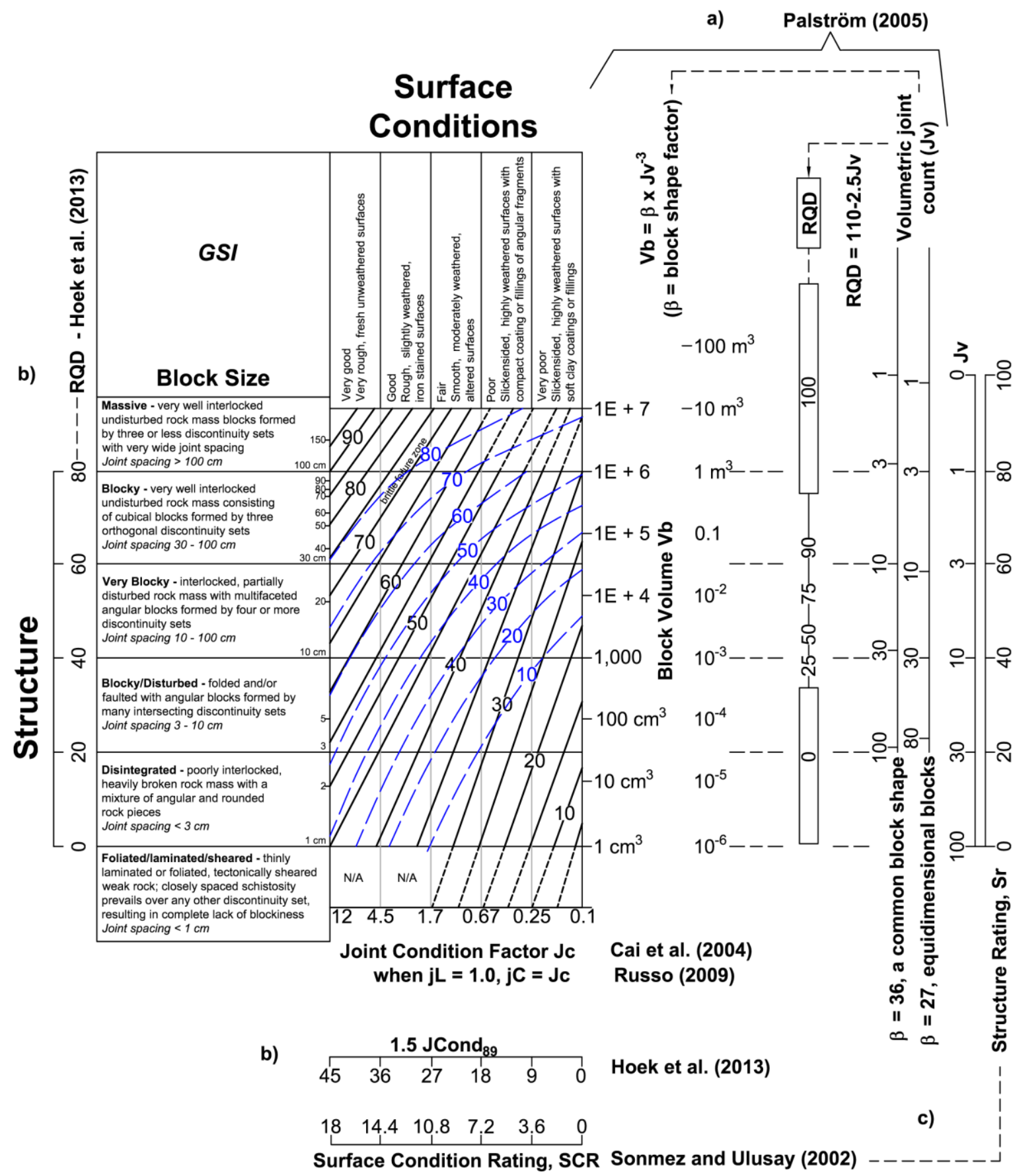

Figure 4 Quantification of GSI chart by Cai et al. (2004). (a) Correlations of Block Volume (Vb) to Rock Quality Designation (RQD) and Volumetric joint count (Jv) after Palmström (2005) presented for comparative purposes. (b) Equivalence of Structure to RQD and Surface Conditions to JCond89, respectively (after Hoek et al. 2013). (c) Equivalence of Structure to Jv and Surface Conditions to Surface Condition Rating (SCR), respectively (after Sonmez and Ulusay 2002) 


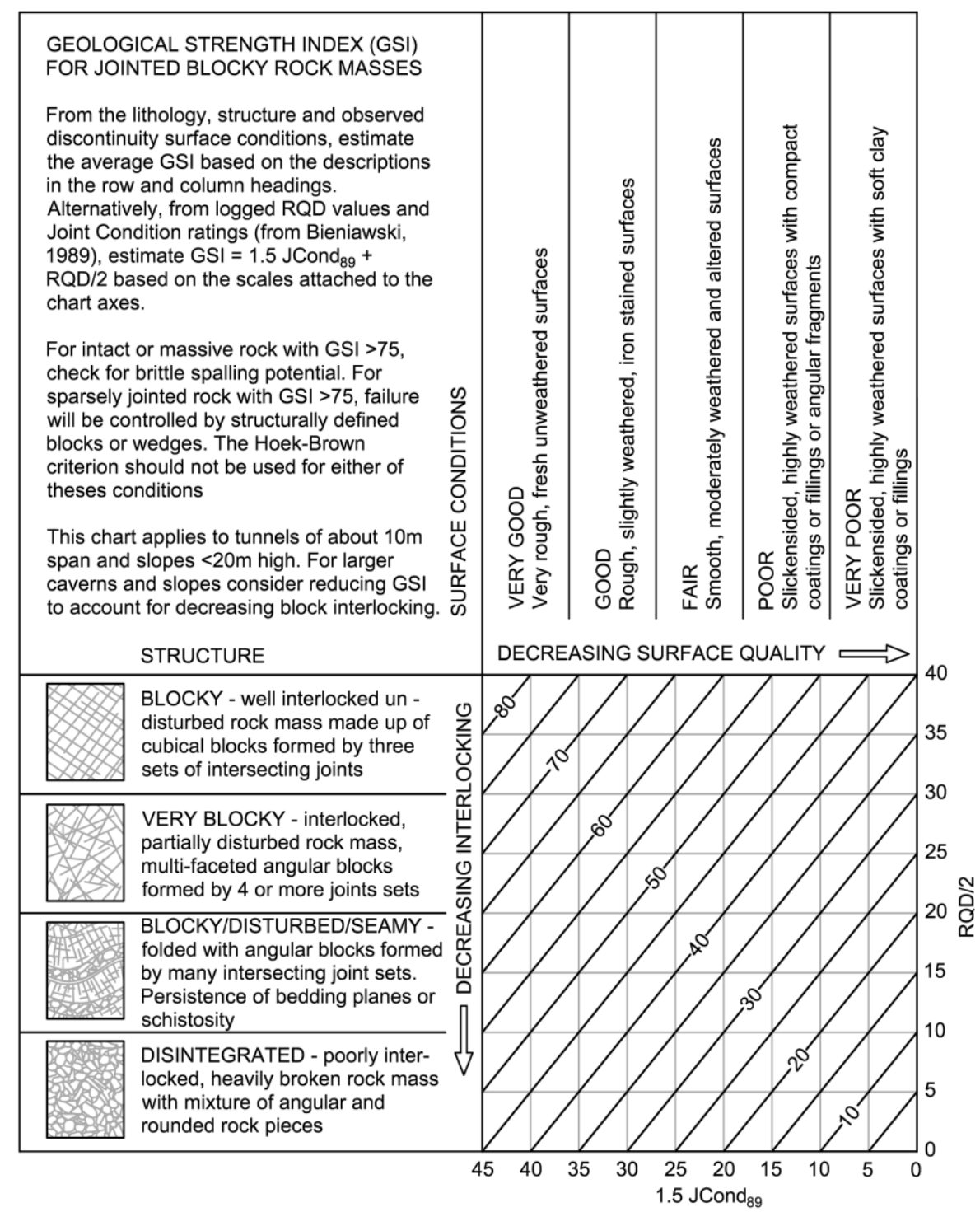

Figure 5 Quantification of GSI chart by Hoek et al. (2013)

There is debate as to what the term interlocking and interlocked actually imply. Russo (2009) emphasises that the descriptions in regard to Structure for GSI are largely based on interlocking rather than the actual degree or scale of fracturing. Kaiser et al. (2015) state that "GSI was developed for excavation stability assessment and support design in rock without interlock and failure processes dominated by block rotation" and further add that "if rock blocks are interlocked, block rotation is inhibited and block failure must occur to create enough kinematic freedom so blocks can rotate, the rock mass should be able to mobilise higher peak strength than suggested" by the HB criterion. The view by these latter authors appears contradictory and this author considers that Kaiser et al. (2015) use the term interlock/ed to define a rock mass where blocks are poorly formed, or absent, as evident in Figures 2(b) and 2(d).

Although Kaiser et al. (2015) consider that Figure 2(c) is not applicable in determining GSI, the author considers that additional blocks could readily develop during loading by development of cracks extending from the defects terminating within the rock blocks and in keeping with the initial descriptions of the HB criterion by Hoek and Brown (1980) wherein "the intact rock pieces will translate, rotate or crush in response to stresses imposed". Moreover, in the author's experience with observations of rock mass failure in slopes, there is often evidence of fracture through intact rock between existing defects.

It would appear that there is varying interpretation of what interlocking constitutes as the term is descriptive rather than relying on a clear definition of how interlocking can be quantified. 


\section{Quantification}

Since inception of GSI there have been several attempts in providing a quantitative manner for assessment and chronologically, these included: Sonmez and Ulusay (1999, 2002), Cai et al. (2004), Russo (2009) and, most recently, Hoek et al. (2013). Each quantification scheme allows definition of an X- and Y-value on the GSI chart.

Figure 4 provides an overview of each of the quantification schemes to allow a broad comparison. The reader should note that within the GSI chart two series of lines are shown in Figure 4. The darker lines are those that were originally proposed by Marinos and Hoek (2000) and these have been respected by the quantifications as proposed by Cai et al. (2004) and Sonmez and Ulusay (2002). The fully dashed lines are the GSI values as proposed by Russo (2009) and under the premise that Palmström's (1995) Joint Condition Factor jC is equivalent to Joint Condition Factor Jc as defined by Cai et al. (2004). Reference should be made to Cai et al. (2004) and Palmström (1995) for a more complete description of all terms.

Recent simplification of the GSI lines by Hoek et al. (2013) are presented in Figure 5 and not shown in Figure 4 to avoid clutter. Hoek et al. (2013) highlight that the bottom and top rows presented in Figure 4 with regard to Structure should not be utilised as inputs for the HB criterion. Hence these rows are absent in Figure 5. The upper row represents massive rock masses where brittle failure phenomena such as rockburst and spalling dominate behaviour in tunnels under high stresses. In the author's experience in large open pit slopes, rock mass stability issues are unlikely in such massive rock types and structurally controlled mechanisms are far more critical to both safety and stability. The bottom row relates to pre-sheared or heavily altered materials and where behaviour is not considered to rely on "sliding and rotation of intact blocks of rock defined by the intersecting discontinuity system". Hoek et al. (2013) recommend the use of the GSI charts in Marinos and Hoek (2001) and Marinos et al. (2007) and highlights that Carter et al. (2008) provide an approach for tackling this end of the competency scale. The approach of Carter et al. (2008) for low GSI and low Unconfined Compressive Strength (UCS) has limited field verification and with two case studies of fault zones encountered in deep tunnels. Dinc et al. (2011) provide an alternative approach that could also be considered. The author notes with the recent advent of high pressure soil triaxial cells: drilling coupled with careful sampling, triaxial testing and judgement may provide a suitable alternative to the approaches of either Carter et al. (2008) or Dinc et al. (2011) in such cases.

\subsection{Structure $-Y$ axis}

Quantification of the Y-axis (Structure in Figures 4 and 5) is made through RQD by Hoek et al. (2013) and by Block Volume for Cai et al. (2004), Russo (2009) and Sonmez and Ulusay (2002).

\subsubsection{RQD approach}

Discussions by Pells et al. (2016) highlight limitations in the use of RQD and suggest that RQD be replaced by fracture frequency or that blockiness be directly assessed from exposure or borehole core photographs. The author disagrees with both of these recommended alternatives for two reasons.

- Duran (2015) has presented an approach for assessment of logging quality where both RQD and fracture frequency are logged. A review of thirty case studies highlighted that fracture frequency is often incorrectly assessed during logging, typically leading to an under-assessment of blockiness and particularly so where poor rock mass conditions are evident.

- Secondly, whilst visual assessment of blockiness appears sound, as indicated by Carter and Marinos (2014) the approach requires caution in exposures to account for weathering and excavation effects (particularly if blasting is used). Furthermore, in the author's opinion the assessment can be unreliable when using core photographs as handling breaks and induced fractures cannot be appropriately accounted for. Russo (2009) highlighted similar concerns with evaluation from examination of core boxes. As emphasised by Kaiser et al. (2015) assessment requires diligent logging practices be applied to ensure open defects are appropriately logged. 
It is interesting to note the proposed differences of RQD versus Structure in Figure 4, with the RQD proposed by Hoek et al. (2013) at variance with the approaches of Cai et al. (2004) and Russo (2009) using the equivalence of RQD proposed by Palmström (2005). Hoek et al. (2013) highlight that their quantified approach is only applicable for slopes with heights less than $20 \mathrm{~m}$ and that for greater heights, consideration is required of "reducing GSI to account for decreasing block interlocking". This suggests that the $\mathrm{Y}$-axis is scale dependent and in keeping with the findings of Douglas and Mostyn (1999).

\subsubsection{Block volume approach}

The use of Block Volume is proposed to quantify Structure by Cai et al. (2004), Russo (2009) and Sonmez and Ulusay (2002) and with Sonmez and Ulusay (2002) suggesting a different scale is applicable. In the author's experience the scale suggested by Sonmez and Ulusay (2002) is inappropriate as it essentially suggests that the transition between Blocky and Very Blocky is nominally at about 100\% RQD. This would result in conservative estimates of Structure for widely spaced rock masses.

The review of logging quality by Duran (2015) highlighted that Block Volume appears to provide poor discernment of changes in blockiness or logging quality.

\subsection{Surface conditions $-\mathrm{X}$ axis}

Distinctly different approaches are utilised in assigning Surface Conditions, the $\mathrm{X}$ axis.

Both Hoek et al. (2013) and Sonmez and Ulusay (2002) propose an additive approach for Surface Conditions, each approach relying on different applications of the defect ratings within the 1989 Rock Mass Rating (RMR89) presented by Bieniawski (1989). Reference should be made to Hoek et al. (2013) and Sonmez and Ulusay (2002) for details of each approach. In the author's experience there are two potential issues with this additive approach and particularly when dealing with borehole data. Firstly, should the assessment be made using the most common/characteristic defects or should it rely on a frequency weighted basis (logging data allowing)? Even though the latter in principle may appear logical, it does not adequately address the presence of 'weak' defects, i.e. faults, shears, clay seams, polished/slickensided etc. Even using a weighted approach the final result is dominated by the common defects and hence assigning a Poor or Very Poor Surface Condition, to what appears as poorer defect conditions is somewhat difficult.

To highlight this aspect Figure 6 presents a rock mass unit wherein Surface Conditions were assessed from borehole core utilising the approaches of Sonmez and Ulusay (2002) (lower left) and Hoek et al. (2013) (upper left) and implementing a weighted approach. The data pertains to an open pit project, where the rock mass unit would only be exposed in the latter stages of mining and consequently slope design relied exclusively on assessment from geotechnical logging of core. The rock mass unit comprised a fresh volcanic mudstone of moderate intact strength, RQD typically very poor and with $34 \%$ of all measured defects comprising shears. Logically such a unit should comprise Very Poor Surface Conditions. However, as evident in Figure 6 the approach by Hoek et al. (2013) indicates Fair/Poor Surface Conditions whilst the approach of Sonmez and Ulusay (2002) indicates Fair Surface Conditions. As such, numerical solutions (such as spreadsheets) to assess GSI by a quantitative manner for borehole core where an additive approach for Surface Conditions is adopted need to be utilised with caution. Although Hoek et al. (2013) indicate that experienced engineering geologist are comfortable with the generic descriptions provided for designation of Surface Quality, it could be argued that there is a large degree of subjectivity in assigning a designation based on the percentage of weak defects present. Moreover, Hoek et al. (2013) indicate that the Surface Conditions should in reality reflect the shear strength of the defects "and it is questionable whether the somewhat arbitrary nature of the roughness and alteration ratings can provide a reliable estimate of shear strength". 

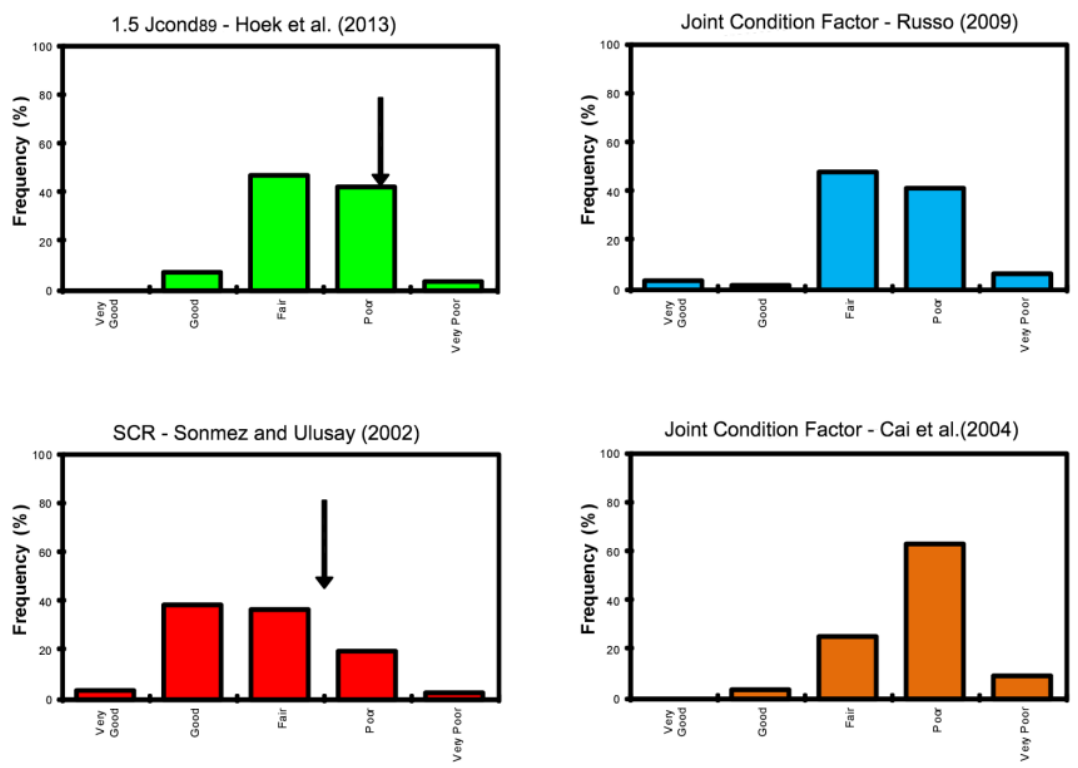

Figure 6 Quantification of Surface Conditions by various approaches for a case selected by author involving assessment from geotechnical logging of core. Arrows highlight assessment adopting approach of Laubscher and Jakubec (2000)

The approaches of Cai et al. (2004) or Russo (2009) to Surface Conditions, using jC or Jc respectively, are somewhat different as the scale is logarithmic based. Log based averaging somewhat compensates for the shortcoming highlighted above. However, as evident in Figure 6, even though the approach of Cai et al. (2004), (lower right) utilising Jc provides the best estimate of Surface Conditions, it still remains partly conservative. The author also highlights that when the assessment is based on borehole core, many of the Palmström inputs require assumptions and particularly those with regards to the large scale waviness of defects $\left(J_{W}\right)$ and continuity $\left(J_{L}\right)$. Moreover, the appropriate assessment of $J_{L}$ requires large scale exposure to assess the end termination of defects.

Laubscher and Jakubec (2000) present an alternative approach to weighting of defect characteristics and suited to a holistic overview of defect characteristics. Essentially a unitary value is applied to the rock mass unit under consideration. The approach was applied to the results of Hoek et al. (2013) and Sonmez and Ulusay (2002) and presented in Figure 6. Interestingly the approach reduces the Surface Condition estimates similar to that of Cai et al. (2004).

\subsection{An alternative view to the axes}

Sullivan (2013) in presenting the Global Slope Performance Index (GSPI) highlighted changes in slope performance as the presence of faults and shears increased. Interestingly Sullivan (2013) provides similar pictorials and descriptions to those provided in the GSI chart for Structure, Figure 5, although no equivalence to GSI is provided. If one applies a nominal equivalence, Sullivan (2013) indicates that for increasing presence of faults and shears (more deformation in the rock mass) a proportional decrease in the Structure designation be assigned (reduction in $\mathrm{Y}$-axis). This approach provides an alternative view in that the quantification schemes of Cai et al. (2004), Hoek et al. (2013), Russo (2009) and Sonmez and Ulusay (2002) consider that an increasing proportion of presence of faults and shears alters Surface Conditions (increase in X-axis).

\section{$5 \quad$ Example cases using available quantification schemes}

The author has utilised two case studies to highlight issues with the available quantification schemes. The case studies were selected in consideration that back-analysis of large scale slope failures were available to allow a comparison with rock mass shear strengths provided by the quantification assessments. 
The quantification assessments utilised data from geotechnical logging of core. Plausible estimates of the Palmström (1995) inputs of jw and jL were provided to defects based on their logged descriptions. GSI quantification was carried out at each logging interval and provides an appreciation of the variability within the rock mass unit. The GSI assessment approaches included those of Cai et al. (2004), Hoek et al. (2013), Russo (2009), Sonmez and Ulusay (2002) and lastly assessing RMR89 and utilising the equivalence suggested by Hoek et al. (1995), i.e. GSI = RMR89 - 5 .

Assessments utilised an EXCEL macro to determine the GSIs for all methods in addition to providing X-Y values for the methods of Cai et al. (2004), Hoek et al. (2013), Russo (2009) and Sonmez and Ulusay (2002) to allow plotting on the respective charts. This graphical presentation has highlighted significant differences between methods. The author highlights that the graphical results utilising the approach of Hoek et al. (2013) are plotted on the GSI chart presented in Marinos and Hoek (2000) to allow a broad comparison with the other methods in terms of allocation of rock mass character in terms of $X$ and $Y$ on the GSI chart.

An issue that arises when considering the variability is the occurrence of zones of no-core or zones of significantly poorer geotechnical properties associated with faults and shear zones. During the quantification assessment phase, the author provided such zones with a nominally low GSI. Where such zones occupy a small portion of the rock mass it can be appropriate to ignore the very low GSI values when determining the overall GSI of the rock mass unit. Although it is of prime importance in understanding the orientation of such faults and shear zones, their potential influence on stability is appropriately addressed as part of stability analyses. For both case studies the influence of structure was taken into account in the back-analyses either by inclusion as explicit structures, where adequate knowledge was available, or through utilising an anisotropic strength function.

\subsection{Case 1}

Case 1 consisted of determining the appropriate rock mass strength for a conglomerate unit towards the toe of a pit wall that was controlling stability. Key aspects of Case 1 include:

- Upper part of slope comprised metamorphics with foliation dipping at a shallow angle into the pit. Pit mapping was available to confirm foliation dips.

- The lower part of the slope comprised a conglomerate unit with evidence of thrust fault structures dipping back into the pit wall. Faults or weak defects comprised $20 \%$ of the logged defects.

- The overall failure mechanism was considered to comprise: sliding on foliation shears within the metamorphics and a complex mechanism at the toe of the slope incorporating a component of rock mass failure (internally within the slope) and sliding on the thrust parallel structures near the toe itself. Evidence of the latter aspect was evident in exposures.

- Significant direct shear testing of foliation, foliation shears, faults and shears was available to allow a high confidence in assigning defect shear strengths.

- The failure involved a slope height of the order of $120 \mathrm{~m}$.

Determination of the rock mass shear strength of the conglomerate is of key importance for the project as it comprises a significant unit that is present in ongoing pit development. Figure 7 provides a summary of the GSI assessments in terms of a visual overview. The median value was assessed ignoring the very low GSI values associated with fault zones, typically with GSI values of 25 or less and evident in the charts as points in the lower right hand corner. A wide range in GSI values is evident, Table 1, significant variation as evident in each chart and interestingly with different areas of the $X-Y$ space populated by each method, Figures 7 (a) to (d). Bertuzzi et al. (2016), Pells et al. (2016) and Russo (2009) all indicate uncertainty in GSI assessment of typically 10 points; however, greater variations are evident in the results for this case. 


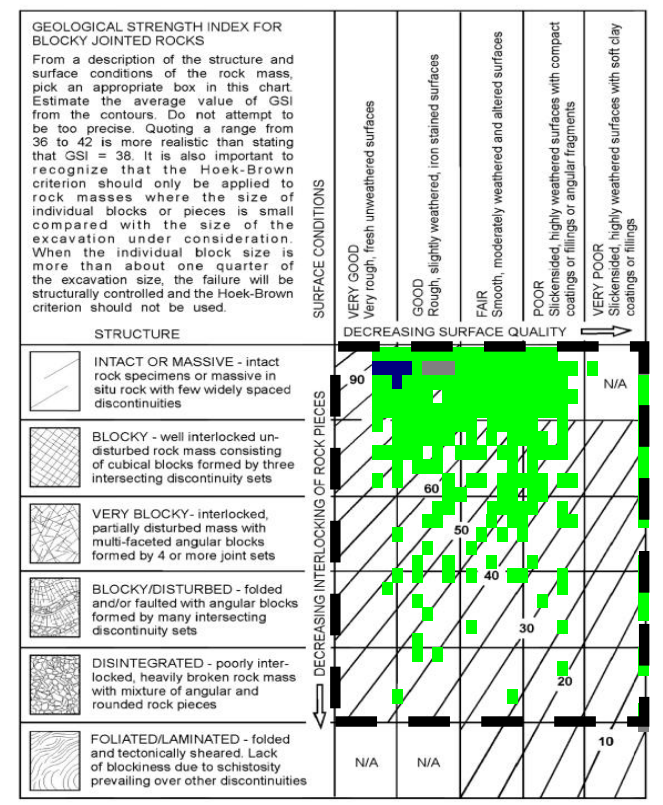

a)

b)
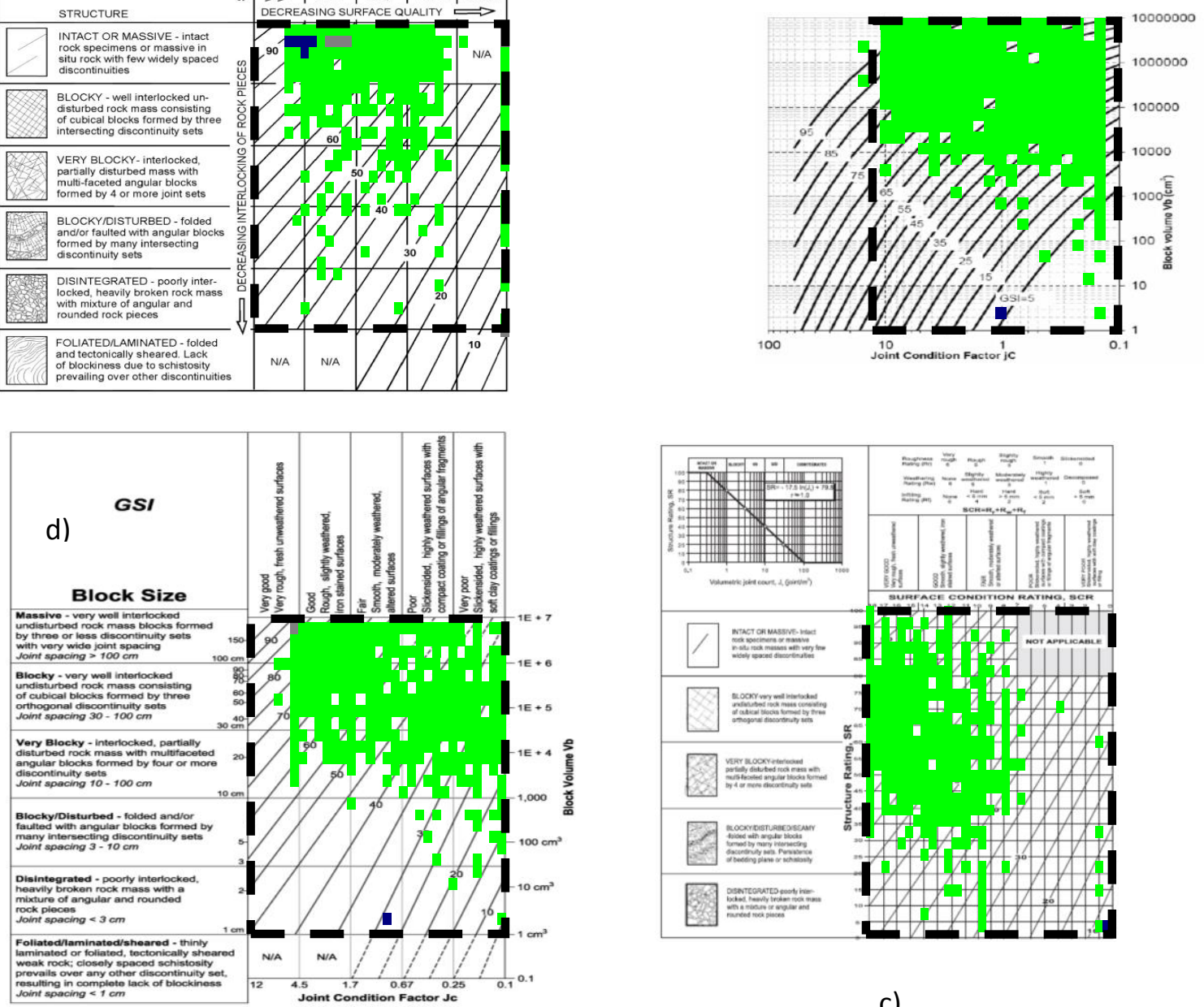

c)

Figure 7 Quantification of conglomerate GSI for Case 1 and presentation on charts, clockwise from top left as proposed by: (a) Hoek et al. (2013), (b) Russo (2009), (c) Sonmez and Ulusay (2002) and (d) Cai et al. (2004) respectively. Note dark dashed box to allow comparison between methods

Table 1 Summary of GSI assessments for Case 1

\begin{tabular}{|cccc}
\hline $\begin{array}{c}\text { GSI quantification } \\
\text { method }\end{array}$ & $\begin{array}{c}\text { Typical } \\
\text { surface conditions }\end{array}$ & $\begin{array}{c}\text { Typical } \\
\text { structure }\end{array}$ & Median GSI \\
\hline Hoek et al. (2013) & Fair/good & Massive & 83 \\
Russo (2009) & Poor/good* & Massive/blocky* & 73 \\
\hline Sonmez and Ulusay (2002) & Very good/good & Blocky/very blocky & 73 \\
\hline Cai et al. (2004) & Poor/good & Massive/blocky & 62 \\
\hline Hoek et al. (1995), GSI = RMR89-5 & NA & NA & 69 \\
\hline
\end{tabular}

* Russo (2009) approach is numerical, a similar schema to Cai et al. (2004) in Figure 4 used to provide qualitative descriptions 
There was a high degree of uncertainty in the intact strength of the conglomerate. Although there was extensive UCS testing, the ratio of sample diameter to clast size was of the order of three to six and there was uncertainty that the UCS was unduly affected by this aspect.

Figure 8 presents the HB criterion utilising the above GSIs, adopting the mean intact strength from the UCS testing and an assumed $\mathrm{mi}$ of 21 . For this case, the rock mass unit was largely within the slope and no disturbance was adopted (i.e. $\mathrm{D}=0$ ). As evident in Figure 8 there is a large difference in rock mass shear strengths with such variations in the quantified GSIs.

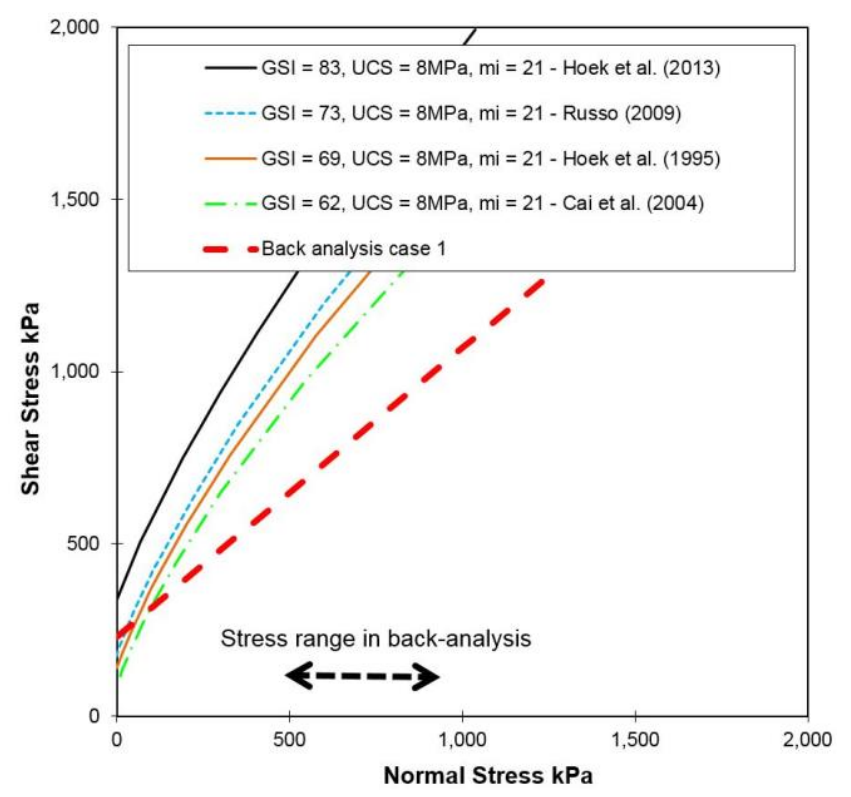

Figure 8 Comparison of rock mass shear strengths for Case 1. Note approach of Sonmez and Ulusay (2002) resulted in same GSI as that of Russo (2009)

The back-analysed strength is presented for comparative purposes and highlights that significantly lower rock mass shear strengths were applicable for the project, compared with those derived from the GSI quantification methods. Checks on the normal stresses at the base of the slices within the conglomerate unit were utilised to provide the stress range noted in Figure 8.

\section{$5.2 \quad$ Case 2}

Case 2 consisted of determining the appropriate rock mass strength for a variably fractured, chloritic altered rock mass unit. Large scale slope instability involved sliding along pit wall parallel faults, with extensive continuities, and with rock mass breakout through the toe of the slope. Slope heights of up to $300 \mathrm{~m}$ were involved.

Figure 9 provides a visual summary of the GSI assessments. Table 2 provides a summary of the GSI assessments for Case 2 with median values assessed ignoring the very low GSI values associated with fault zones. The range in GSI values (13 points) is not as pronounced as that encountered in Case 1 (21 points). Of note is that the assessment of both Sonmez and Ulusay (2002) and Hoek et al. (2013) assigned better Surface Conditions combined with poorer Structure to result in similar GSI assessments to that of Cai et al. (2004) and Russo (2009) wherein poorer Surface Conditions were coupled with slightly improved Structure. This is evident in the visual presentations where the first two approaches, Figures 9 (a) and (c) typically plot at lower left of centre in the $X-Y$ space and with and the latter two methods just marginally above and right of centre, Figures 9 (b) and (d). 


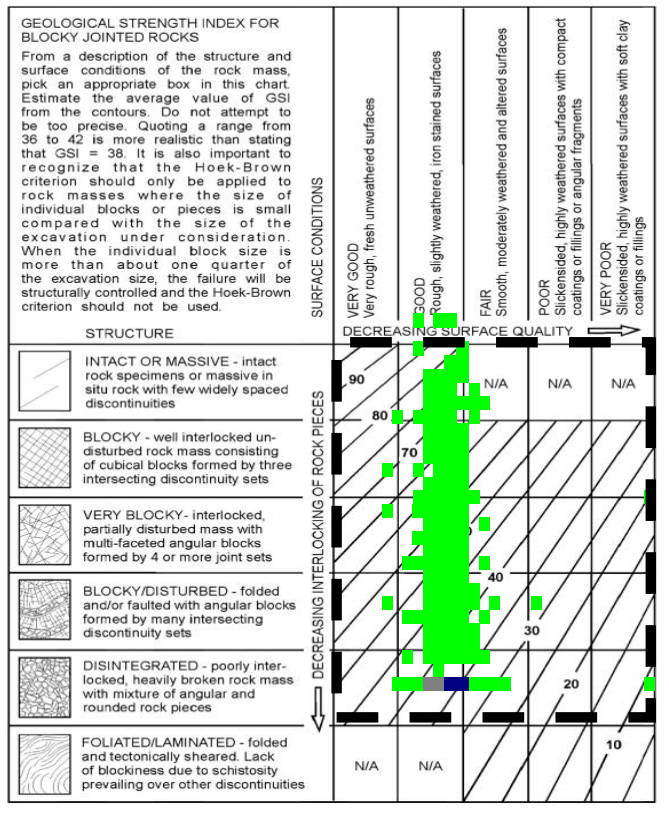

a)

b)
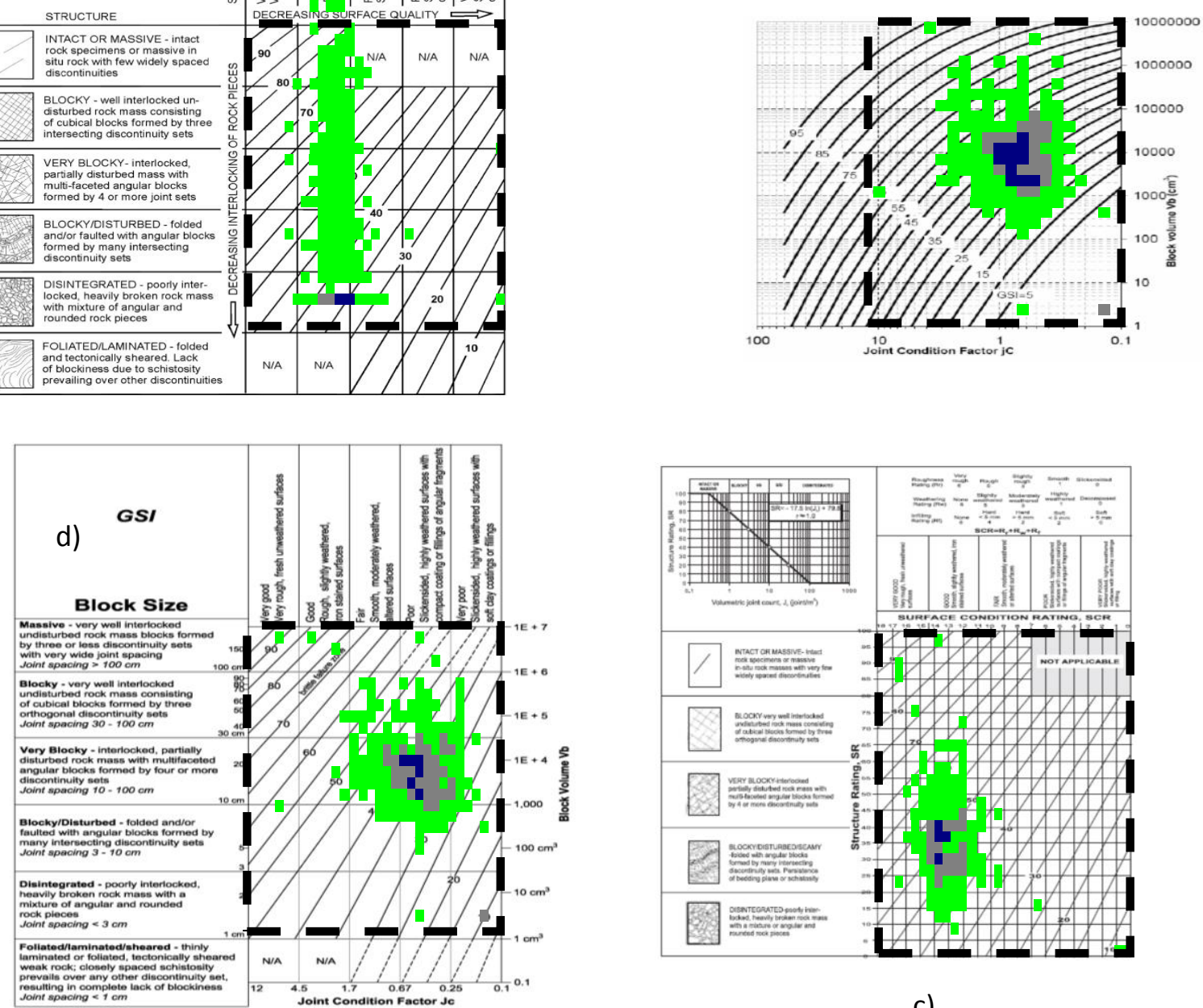

c)

Figure 9 Quantification of GSI for Case 2 and presentation on charts, clockwise from top left as proposed by: (a) Hoek et al. (2013), (b) Russo (2009), (c) Sonmez and Ulusay (2002); and, (d) Cai et al. (2004) respectively. Note dark dashed box to allow comparison between methods

Table 2 Summary of GSI assessments for Case 2

\begin{tabular}{cccc}
\hline $\begin{array}{c}\text { GSI quantification } \\
\text { method }\end{array}$ & $\begin{array}{c}\text { Typical } \\
\text { surface conditions }\end{array}$ & $\begin{array}{c}\text { Typical } \\
\text { structure }\end{array}$ & Median GSI \\
\hline Hoek et al. (2013) & Good & Blocky/disintegrated & 41 \\
\hline Russo (2009) & Poor/fair* & Blocky/very blocky* & 49 \\
Sonmez and Ulusay (2002) & Good & Very blocky/disturbed & 49 \\
\hline Cai et al. (2004) & Poor/fair & Blocky/very blocky & 39 \\
\hline Hoek et al. (1995), GSI = RMR89-5 & NA & NA & 52 \\
\hline
\end{tabular}

* Russo (2009) approach is numerical, a similar schema to Cai et al. (2004) in Figure 4 used to provide qualitative descriptions 
For this case the approaches where Surface Conditions are based on an additive approach, Hoek et al. (2013) and Sonmez and Ulusay (2002), the combination of fresh rock, rough surfaces, thin but soft chlorite infills on predominantly joints results in Good Surface Conditions. Whereas the Palmström based approaches, Figures 9 (b) and (d), indicate typically Fair/Poor Surface Conditions.

Figure 10 presents a comparison of the rock mass shear strengths based on the quantification assessments coupled with UCS and mi values assigned within the project. For this case, the rock mass component of the failures was largely within the slope and no disturbance was adopted (i.e. $D=0$ ). The results of back-analyses indicate lower rock mass shear strengths are applicable compared with those derived from the GSI quantification methods.

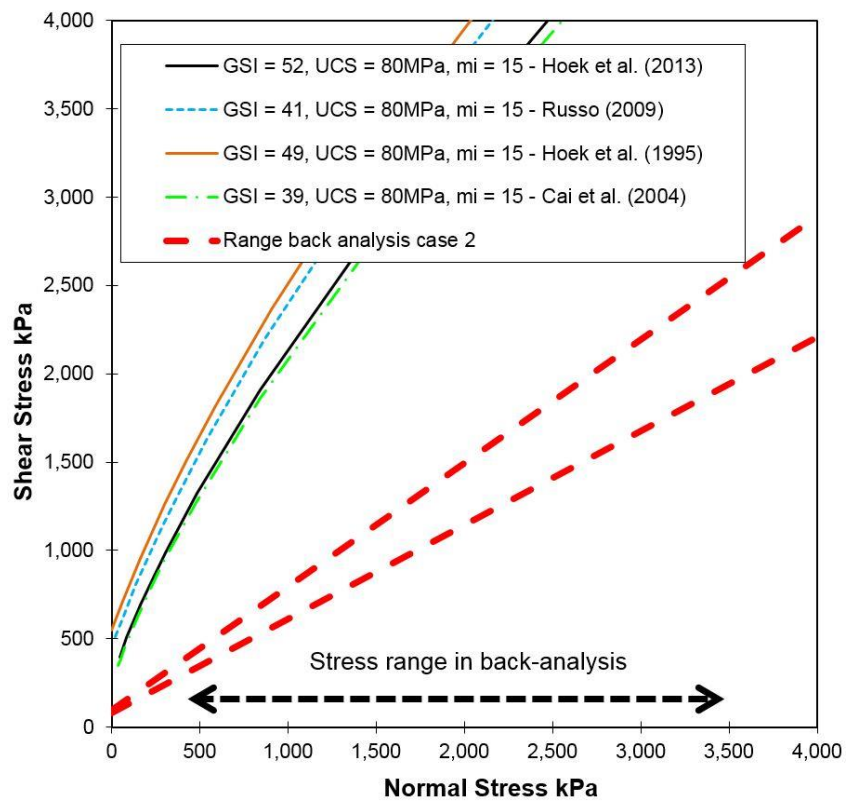

Figure 10 Comparison of rock mass shear strengths for Case 2. Note approach of Sonmez and Ulusay (2002) resulted in same GSI as that of Russo (2009)

\section{Conclusion}

Comparison of the different methods and for the two cases presented highlights the following aspects:

- The quantitative methods of Cai et al. (2004), Hoek et al. (2013), Sonmez and Ulusay (2002) and Russo (2009) each appear to provide a different view as to the allocation of rock mass character in terms of $X$ and $Y$ on the GSI chart.

- Methods of Russo (2009) and Sonmez and Ulusay (2002) have provided similar GSIs to those provided by assessing RMR89 and utilising the equivalence suggested by Hoek et al. (1995), i.e. $\mathrm{GSI}=\mathrm{RMR} 89$ - 5. Based on quantified GSIs, all three methods overestimated rock mass strengths.

- For both cases, quantified GSIs utilising Hoek et al. (2013) overestimated the rock mass strength and with the overestimation being significant where high RQDs are present.

- The method of Cai et al. (2004) appears to provide the closest estimate of the rock mass strengths from the quantified GSIs, albeit the assessments are conservative estimates for both cases.

- The author considers that for both of the presented cases the character of the defects has played a critical role in the large scale slope stability. As highlighted by the example in Figure 6 this infers the current methodologies of assigning Surface Conditions, particularly where a significant percentage of weak defects are present in the rock mass, results in overestimation of GSI.

- Review of further case studies are planned to allow refinement of the quantification schemes and their applicability to large scale pit slopes. 


\section{References}

Bertuzzi, R, Douglas, DJ \& Mostyn, G 2016, 'Comparison of quantified and chart GSI for four rock masses', Engineering Geology, vol. 202, pp. 24-35.

Bieniawski, ZT 1989, Engineering Rock Mass Classification, New York, Wiley Interscience.

Cai, M, Kaiser, PK, Uno, H, Tasaka, Y \& Minami, M 2004, 'Estimation of rock mass deformation modulus and strength of jointed hard rock masses using the GSI system', International Journal of Rock Mechanics and Mining Sciences, vol. 41, pp. 3-19.

Carter, TG \& Marinos, V 2014, 'Use of GSI for rock engineering design', in Proceedings 1st International Conference on Applied Empirical Design Methods in Mining, Lima, pp. 1-19.

Carter, TG, Diederichs, MS \& Carvalho, JL 2008, 'Application of modified Hoek-Brown transition relationships for assessing strength and post-yield behaviour at both ends of the rock competence scale', Journal of the Southern African Institute of Mining and Metallurgy, vol. 108, no. 6, pp. 325-338.

Cundall, PA, Pierce, ME \& Mas Ivars, D 2008, 'Quantifying the size effect of rock mass strength', in Y Potvin, J Carter, A Dyskin, R Jeffrey (eds), 1st Southern Hemisphere International Rock Mechanics Symposium, Australian Centre for Geomechanics, Perth, pp. 3-15.

Dinc, OS, Sonmez, H, Tunusluoglu, C \& Kasapoglu, KE 2011, 'A new general empirical approach for the prediction of rock mass strengths of soft to hard rock masses', International Journal of Rock Mechanics and Mining Sciences, vol. 48, pp. 650-665.

Douglas, KJ \& Mostyn, G 1999, 'Strength of large rock masses - field verification, Rock Mechanics for Industry', in Proceedings of the 37th US Rock Mechanics Symposium, Vale Colorado, Balkema Rotterdam, vol. 1, pp. 271-276.

Duran, A 2015, '30 Case Studies: Using borehole data for rock mass quality assessment', in Proceedings Slope Stability 2015, Cape Town.

Hoek, E 1983, 'Strength of jointed rock masses', 23rd Rankine Lecture, Géotechnique, vol. 33, no. 3, pp. 187-223.

Hoek, E \& Brown, ET 1980, 'Empirical strength criterion for rock masses', Journal of the Geotechnical Engineering Division, vol. 106, pp. 1013-1035.

Hoek, E \& Brown, ET 1997, 'Practical estimates of rock mass strength', International Journal of Rock Mechanics and Mining Sciences, vol. 34, pp. 1165-1186.

Hoek, E, Carter, TG \& Diederichs, MS 2013, 'Quantification of the Geological Strength Index chart', in 47th US Rock Mechanics/Geomechanics Symposium, ARMA 13-672, San Francisco.

Hoek, E, Kaiser, PK \& Bawden, WF 1995, Support of underground excavations in hard rock, Rotterdam, Balkema.

Hoek, E, Marinos, P \& Benissi, M 1998, 'Applicability of the geological strength index (GSI) classification for very weak and sheared rock masses. The case of the Athens Schist Formation', Bulletin of Engineering Geology and the Environment, vol. 57, no. 2, pp. 151-160.

Hoek, E, Marinos, P \& Marinos, V 2005, 'Characterisation and engineering properties of tectonically undisturbed but lithologically varied sedimentary rock masses', International Journal of Rock Mechanics and Mining Sciences, vol. 42, pp. 277-285.

Kaiser, PK, Amann, F \& Bewick, BP, 2015, 'Overcoming challenges of rock mass characterization for underground construction in deep mines', in The 13th International Congress of Rock Mechanics, Montreal.

Laubscher, DH \& Jakubec, J 2000, 'The IRMR/MRMR rock mass classification system for jointed rock masses', Society for Mining, Metallurgy, and Exploration, pp. 475-481.

Marinos, PV 2010, 'New proposed GSI classification charts for weak or for complex rock masses', in 12th International Congress of Geological Society of Greece, Patras, pp. 1248-1258.

Marinos, P \& Hoek, E 2000, 'GSI: A geologically friendly tool for rock mass strength estimation', in GeoEng2000: An International Conference on Geotechnical \& Geological Engineering, International Society for Rock Mechanics, Melbourne, pp. 1422-1442.

Marinos, P \& Hoek, E 2001, 'Estimating the geotechnical properties of heterogeneous rock masses such as flysch', Bulletin of Engineering Geology and the Environment, vol. 60, pp. 85-92.

Marinos, P, Hoek, E \& Marinos, V 2005, 'Variability of the engineering properties of rock masses quantified by the geological strength index: the case of ophiolites with special emphasis on tunnelling', Bulletin of Engineering Geology and the Environment, vol. 65, pp. 129-142.

Marinos, P, Marinos, V \& Hoek, E 2007, 'Geological Strength Index (GSI). A characterization tool for assessing engineering properties for rock masses', in M Romana, A Perucho \& C Olalla (eds), Underground Works Under Special Conditions, Taylor and Francis, Lisbon, pp. 13-21.

Palmström, A 1995, RMi - A Rock Mass Characterisation System for Rock Engineering Purposes, University of Oslo, Norway.

Palmström, A 2005, 'Measurements of and correlations between block size and Rock Quality Designation (RQD)', Tunnels and Underground Space Technology, vol. 20, pp. 326-377.

Pells, PJN, Bieniawski, ZT, Hencher, SR \& Pells, SE 2016, 'A reappraisal of the use of RQD in rock mass assessment', in press.

Russo, G 2009, 'A new rational method for calculating the GSI', Tunnelling and Underground Space Technology, vol. 24, pp. 103-111.

Sonmez, H \& Ulusay, R 1999, 'Modifications to the geological strength index (GSI) and their applicability to stability of slopes', International Journal of Rock Mechanics and Mining Sciences, vol. 36, pp. 743-760.

Sonmez, H \& Ulusay, R 2002, 'A discussion on the Hoek-Brown failure criterion and suggested modification to the criterion verified by slope stability case studies, Yerbilimleri, vol. 26, pp. 77-99.

Sullivan, TD 2013, 'Global Slope Performance Index', in PM Dight (ed.), Proceedings of the International Symposium on Slope Stability in Open Pit Mining and Civil Engineering, Australian Centre for Geomechanics, Perth, pp. 55-80. 